Published in final edited form as:

J Labelled Comp Radiopharm. 2018 April ; 61(4): 391-394. doi:10.1002/jlcr.3598.

\title{
Synthesis of [ $\left.{ }^{15} \mathrm{~N}\right]-$ Cholamine Bromide Hydrobromide
}

\author{
Judy Szeto, Remy Lemoine, Rosary Nguyen, Lori L. OIson, and Mary J. Tanga
}

SRI International, Biosciences Division 333 Ravenswood Ave, Menlo Park, CA 94025 USA

\begin{abstract}
$\left[{ }^{15} \mathrm{~N}\right]$-Cholamine is an isotope tag for metabolomics research, because it possesses two important properties: an NMR active isotope and a permanent charge for MS sensitivity. Here we present a scalable synthesis of $\left[{ }^{15} \mathrm{~N}\right]$-cholamine.
\end{abstract}

\section{Graphical abstract}

$\mathrm{Br}^{-}$

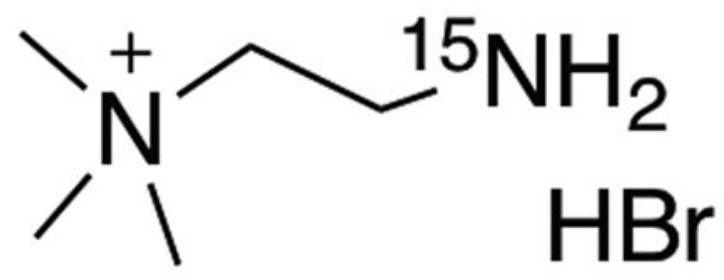

\section{Keywords}

$\left[{ }^{15} \mathrm{~N}\right]$-Cholamine bromide hydrobromide; smart isotope tag; chemo-selective tag; carboxylic acid metabolites

\section{Introduction}

The field of metabolomics seeks to characterize and quantify small molecules found in a biological system. This task is simplified if two analytical methods can be used in tandem, such as exploiting the combined strengths of NMR (nuclear magnetic resonance) and MS (mass spectrometry) for the identification of unknown metabolites. Stable isotope labelling is a strategy that increases the reliability of identification. $\left[{ }^{15} \mathrm{~N}\right]-$ Cholamine $\left(2-\left(\left[{ }^{15} \mathrm{~N}\right]-\right.\right.$ amino)- $N, N, N$-trimethylethanaminium) has been shown to be a promising tag for NMR- and MS-based profiling of metabolites containing carboxylic acid moieties. ${ }^{1}$ Carboxylic acids represent one of the four major functional groups in the metabolome, along with amines, alcohols, and carbonyls. These four groups cover $95 \%$ of the 8,000 endogenous human metabolites in the Human Metabolome Database. ${ }^{2}$

Correspondence to: Mary J. Tanga.

Conflict of Interest: The authors did not report any conflict of interest. 


\section{Results and discussion}

There is only one reported synthesis of $\left[{ }^{15} \mathrm{~N}\right]$-cholamine as its chloride hydrochloride salt as shown in Scheme 1. ${ }^{1}$ The literature sequence involves the reaction of $\left[{ }^{15} \mathrm{~N}\right]$-phthalimide potassium salt $\left(\mathbf{1}^{*}\right)$ with (2-bromoethyl)trimethylammonium bromide (2), followed by a two-step deprotection of the phthalimido group. The product is obtained by precipitation followed by several washes to remove the phthalic acid byproduct of the hydrolysis reaction. 1

To support the NIH Common Fund's Metabolomics Program, a larger quantity of [ $\left.{ }^{15} \mathrm{~N}\right]-$ cholamine was needed. We first considered the scalability of the published procedure.

Notably, yields were not included in the report. Using unlabeled phthalimide potassium (1), we were not able to scale-up the literature procedures in a satisfactory manner. The limitations of the reported process were two-fold. First, the reaction of phthalimide potassium salt (1) with (2-bromoethyl)trimethylammonium bromide (2) proceeded in a modest $45 \%$ yield. We attributed the low yield to the decomposition of the alkylating reagent and the elimination of the trimethylammonium group in the alkylated product. Both compounds are susceptible to a Hofmann elimination reaction. Second, the hydrolysis of the phthalimido group proceeded as expected however, isolation of pure product was challenging. Removal of the phthalic acid byproduct from the desired product could not be done efficiently. Most of the target compound was washed away along with the impurity.

This led us to explore an alternative method that would be amenable to the production of $\left[{ }^{15} \mathrm{~N}\right]$-cholamine on large scale. Exploratory experiments were first run using unlabeled starting material. Scheme 2 describes the final iteration of the synthesis that we developed and the scale at which the reactions were ran.

The issue with the decomposition of the alkylating agent in the literature procedure was solved by using 1,2-dibromoethane (6) instead of (2-bromoethyl)trimethylammonium bromide (2). ${ }^{3}$ Precipitation led to the isolation of the alkylated product 7 in $85 \%$ yield. ${ }^{3}$ The trimethylammonium group was then introduced by displacing the bromide of compound 7 with trimethylamine. Our new two-step synthesis of intermediate $\mathbf{3}$ from phthalimide potassium (1) was more efficient than the one-step method described previously ( $71 \%$ vs. $45 \%)$, and $18 \mathrm{~g}$ of $\mathbf{3}$ was synthesized by this new protocol.

The separation of phthalic acid from the desired product was solved by deprotecting the primary amino group using hydrazine. Instead of phthalic acid, 1,3-dihydrophthalazine-1,4dione byproduct is formed. The latter compound was insoluble under the reaction conditions and readily removed from the reaction mixture by filtration. Concentration of the filtrate gave pure cholamine bromide (8). The target bromide hydrobromide $\mathbf{9}$ was formed by treatment of $\mathbf{8}$ with hydrogen bromide (69\% yield from 3 ). The overall yield of unlabeled cholamine bromide hydrobromide (9) from phthalimide potassium salt (1) was $49 \%$ with only simple filtration and trituration for purification. The process was applied to the synthesis of $10.5 \mathrm{~g}$ of $\mathbf{9} .^{4}$ 
Following the process developed with unlabeled materials, three similar scaled runs for the preparation of $\left[{ }^{15} \mathrm{~N}\right]$-cholamine bromide hydrobromide $\left(\mathbf{9}^{*}\right)$ were performed (Scheme 3 ). Gratifyingly, using $\left[{ }^{15} \mathrm{~N}\right]$-phthalimide potassium salt $\left(\mathbf{1}^{*}\right)$ in the improved four-step synthesis of $\left[{ }^{15} \mathrm{~N}\right]$-cholamine proceeded in good overall yield $\left(52 \% \mathbf{9}^{*}\right.$ from $\mathbf{1}^{*}, 23.9 \mathrm{~g}, 10 \mathrm{~g}$, and $11 \mathrm{~g})$.

\section{Conclusion}

An efficient, scalable, and operationally straightforward synthesis of $\left[{ }^{15} \mathrm{~N}\right]$-cholamine was developed, which is an improvement over the previously described route. ${ }^{1}$ The intermediates and final product were isolated by simple filtration and trituration, and the synthesis was demonstrated for as much as $23.9 \mathrm{~g}$ of $\left[{ }^{15} \mathrm{~N}\right]$-cholamine bromide hydrobromide.

\section{Experimental}

\section{General methods}

All reactions were carried out using commercial reagents of the highest grade and without further purification. $\left[{ }^{15} \mathrm{~N}\right]$-Phthalimide potassium salt was purchased from Aldrich. NMR spectra were measured on a Varian $400 \mathrm{MHz}$ instrument. Chemical shifts are reported in parts per million $(\delta)$ downfield from tetramethylsilane. Elemental analysis was performed by ASL Environmental. Liquid chromatography-mass spectrometry (LCMS) data were obtained using a Thermo LCQ Fleet and Finnigan Surveyor System with a SeQuat ZICpHILIC $5 \mu \mathrm{m}$ polymeric $(50 \times 4.6 \mathrm{~mm})$ column using $25 \mathrm{nM}$ ammonium acetate $(\mathrm{pH} 9)$ in water/acetonitrile $(30 / 70, \mathrm{v} / \mathrm{v})$ as the mobile phase at a flow rate of $0.5 \mathrm{~mL} / \mathrm{min}$ with a ESI positive ion mode, full scale $(50-300 \mathrm{~m} / \mathrm{z})$.

$\left[{ }^{15} \mathrm{~N}\right]-2-(2-B r o m o e t h y l) i s o i n d o l i n e-1,3-d i o n e ~\left(7^{\star}\right)$-In a dried round-bottom flask with a magnetic stir bar, $\left[{ }^{15} \mathrm{~N}\right]$-phthalimide potassium salt $\left(\mathbf{1}^{*}, 28 \mathrm{~g}, 0.151 \mathrm{~mol}\right)$ was dissolved in $57 \mathrm{~mL}$ of $\mathrm{N}, \mathrm{N}$-dimethylformamide and the resulting solution was cooled to $0{ }^{\circ} \mathrm{C}$ under inert atmosphere. At $0{ }^{\circ} \mathrm{C}, 1,2$-dibromoethane $(6,40 \mathrm{~mL}, 0.464 \mathrm{~mol}, 3.0$ equiv.) was then added to the reaction flask. The reaction mixture was allowed to warm to room temperature and stirred for $48 \mathrm{~h}$ before being quenched with water $(50 \mathrm{~mL})$. The reaction mixture was extracted with ethyl acetate $(3 \times 100 \mathrm{~mL})$. The combined organic layers were then washed with water $(2 \times 50 \mathrm{~mL})$ followed by brine $(50 \mathrm{~mL})$ before being dried with sodium sulfate and concentrated. The residue was dried under vacuum to give intermediate 7 as a white solid (27.7 g, 71\% yield). ${ }^{1} \mathrm{H}$ NMR $\left(400 \mathrm{MHz}, \mathrm{CDCl}_{3}\right) \delta 7.87-7.85(\mathrm{~m}, 2 \mathrm{H})$, 7.74-7.72 (m, 2H), 4.10 (td, $J=6.8,1.1 \mathrm{~Hz}, 2 \mathrm{H}), 3.6$ (td, $J=6.7,2.3 \mathrm{~Hz}, 2 \mathrm{H}) .{ }^{13} \mathrm{C}$ NMR $\left(100 \mathrm{MHz}, \mathrm{CDCl}_{3}\right) \delta 167.8\left(\mathrm{~d}, J_{13 \mathrm{C}-15 \mathrm{~N}}=18.4 \mathrm{~Hz}\right), 133.9\left(\mathrm{~d}, J_{13 \mathrm{C}-15 \mathrm{~N}}=22.9 \mathrm{~Hz}\right), 131.8(\mathrm{~d}$, $\left.J_{13 \mathrm{C}-15 \mathrm{~N}}=10.7 \mathrm{~Hz}\right), 123.4\left(\mathrm{~d}, J_{13 \mathrm{C}-15 \mathrm{~N}}=27.4 \mathrm{~Hz}\right), 39.2\left(\mathrm{~d}, J_{13 \mathrm{C}-15 \mathrm{~N}}=13.7 \mathrm{~Hz}\right), 28.1$.

[ $\left.{ }^{15} \mathrm{~N}\right]-2-(1,3-D i o x o i s o i n d o l i n-2-y l)-N, N, N-t r i m e t h y l e t h a n-1-a m i n i u m ~ b r o m i d e ~\left(3^{*}\right)$ -In a $420 \mathrm{~mL}$ sealed-tube flask (Chemglass) with a magnetic stir bar, $2 \mathrm{M}$ trimethylamine in tetrahydrofuran ( $218 \mathrm{~mL}, 0.436 \mathrm{~mol}, 4$ equiv.) was added to intermediate $7 *(27.7 \mathrm{~g}$, $0.109 \mathrm{~mol}$ ) under inert atmosphere. The resulting solution was heated at $55^{\circ} \mathrm{C}$ for $24 \mathrm{~h}$. The reaction mixture was then transferred to a flask using dichloromethane and concentrated. The white solid was then washed with dichloromethane $(3 \times 60 \mathrm{~mL})$, filtered, and dried 
under vacuum to obtain $3^{*}$ as a white solid (33 g, 97\% yield). ${ }^{1} \mathrm{H}$ NMR (400 $\left.\mathrm{MHz}, \mathrm{CDCl}_{3}\right)$ $\delta$ 7.78-7.74 (m, 2H), 7.73-7.68 (m, 2H), $4.04(\mathrm{t}, J=7.0 \mathrm{~Hz}, 2 \mathrm{H}), 3.54(\mathrm{td}, J=7.2,1.6 \mathrm{~Hz}$, 2H), $3.11(\mathrm{~s}, 9 \mathrm{H}) .{ }^{13} \mathrm{C} \mathrm{NMR}\left(100 \mathrm{MHz}, \mathrm{CDCl}_{3}\right) \delta 169.6\left(\mathrm{~d}, J_{13 \mathrm{C}-15 \mathrm{~N}}=13.7 \mathrm{~Hz}\right), 135.0$, $131.1\left(\mathrm{~d}, J_{13 \mathrm{C}-15 \mathrm{~N}}=9.2 \mathrm{~Hz}\right), 123.6,63.5,53.2\left(\mathrm{~d}, J_{13 \mathrm{C}-15 \mathrm{~N}}=4.6 \mathrm{~Hz}\right), 31.6\left(\mathrm{~d}, J_{13 \mathrm{C}-15 \mathrm{~N}}=\right.$ $13.7 \mathrm{~Hz})$.

[ $\left.{ }^{15} \mathrm{~N}\right]-2-A m i n o-N, N, N-t r i m e t h y l e t h a n a m i n i u m ~ b r o m i d e ~\left(8^{*}\right)$-In a round-bottom flask with a magnetic stir bar, intermediate $3 *(17 \mathrm{~g}, 0.054 \mathrm{~mol})$ was suspended in $271 \mathrm{~mL}$ of a 7:3 (v/v) mixture of chloroform and ethanol, and the solution was cooled to $0{ }^{\circ} \mathrm{C}$. Aqueous hydrazine monohydrate ( $64 \%$ (w/w), $6.2 \mathrm{~mL}, 0.081 \mathrm{~mol}, 1.5$ equiv.) was added dropwise. After the addition, the reaction became homogenous and was stirred at $50{ }^{\circ} \mathrm{C}$ for $12 \mathrm{~h}$ with a reflux condenser under inert atmosphere. The white precipitate that formed was removed by filtration and washed with an 8.5:1.5 mixture (v/v) of chloroform and ethanol (3 $\times 50 \mathrm{~mL}$ ). The filtrate was concentrated and dried under vacuum. The residue was used in next step without purification or characterization.

\section{[ $\left.{ }^{15} \mathrm{~N}\right]-2-A m i n o-\mathrm{N}, \mathrm{N}, \mathrm{N}$-trimethylethanaminium bromide, hydrobromide salt} $\left(\left[{ }^{15} \mathrm{~N}\right]\right.$-Cholamine bromide hydrobromide salt) $\left(\mathbf{9}^{\star}\right)$-Compound $\mathbf{8}^{*}$ (from process above, theoretical $0.054 \mathrm{~mol}$ ) was dissolved in $54 \mathrm{~mL}$ of deionized water and the solution was cooled to $0{ }^{\circ} \mathrm{C}$. At $0{ }^{\circ} \mathrm{C}$, aqueous hydrobromic acid $(48 \%, 13.7 \mathrm{~mL})$ was added dropwise, and the resulting slurry was stirred at $0{ }^{\circ} \mathrm{C}$ for $1 \mathrm{~h}$. The reaction mixture was evaporated and then co-evaporated with a toluene and methanol mixture (4.5:0.5, $2 \times 25$ $\mathrm{mL}$ ) at $45^{\circ} \mathrm{C}$. When half of the solvent had been removed, the white precipitate was filtered and then washed with water $(2 \times 10 \mathrm{~mL})$. The filtrate was further evaporated with toluene and methanol mixture, and the residue was dried under vacuum. The solid was triturated with minimal amounts of methanol $(3 \times 15 \mathrm{~mL})$, filtered, and dried under vacuum to provide $\left[{ }^{15} \mathrm{~N}\right]$-cholamine bromide hydrobromide salt $\left(\mathbf{9}^{*}, 11 \mathrm{~g}, 76 \%\right.$ yield). ${ }^{1} \mathrm{H} \mathrm{NMR}(400 \mathrm{MHz}$, $\left.\mathrm{D}_{2} \mathrm{O}\right) \delta 3.62-3.58(\mathrm{~m}, 2 \mathrm{H}), 3.45-3.41(\mathrm{~m}, 2 \mathrm{H}), 3.12(\mathrm{~s}, 9 \mathrm{H}) .{ }^{13} \mathrm{C} \mathrm{NMR},\left(100 \mathrm{MHz}, \mathrm{D}_{2} \mathrm{O}\right) \delta$ $61.3,53.6,32.9\left(\mathrm{~d}, \mathrm{~J}_{13 \mathrm{C}-15 \mathrm{~N}}=7.7 \mathrm{~Hz}\right)$. MS, theory for $\mathrm{C}_{5} \mathrm{H}_{15} \mathrm{~N}^{15} \mathrm{~N}^{+}: \mathrm{m} / \mathrm{z}=104.12$; found $\mathrm{m} / \mathrm{z}=104.11$. Elemental analysis, calcd for $\mathrm{C}_{5} \mathrm{H}_{16} \mathrm{Br}_{2} \mathrm{~N}^{15} \mathrm{~N}$ : C, 22.66\%; $\mathrm{H}, 6.09 \% ; \mathrm{N}$, $10.95 \%$; Br, 60.31\%; found C, $22.50 \pm 0.07 \% ; \mathrm{H}, 6.05 \pm 3.6 \%$; N, $10.45 \pm 0.1 \%$; Br, 58.46 $\pm 3 \%$.

Using the above procedures, three batches of $\left[{ }^{15} \mathrm{~N}\right]$-cholamine bromide hydrobromide salt were prepared ( $44.9 \mathrm{~g}$ total). ${ }^{4}$

\section{Acknowledgments}

This project has been funded in whole or in part with Federal funds from the National Heart, Lung, and Blood Institute, National Institutes of Health, Department of Health and Human Services, Contract No. HHSN268201300022C

\section{References}

1. Tayyari F, Gowda GAN, Gu H, Raftery D. ${ }^{15} \mathrm{~N}$-Cholamine - a smart isotope tag for combining NMR- and MS-based metabolite profiling. Anal Chem. 2013; 85:8715-8721. [PubMed: 23930664]

2. Wishart DS, Jewison T, Guo AC, Wilson M, Knox C, Liu Y, Djoumbou Y, Mandal R, Aziat F, Dong E, Bouatra S, Sinelnikov I, Arndt D, Xia J, Liu P, Yallou F, Bjorndahl T, Perez-Pineiro R, Eisner R, 
Allen F, Neveu V, Greiner R, Scalbert A. HMDB 3.0-The human metabolome database in 2013. Nucleic Acids Res. 2013; 41:D801-7. [PubMed: 23161693]

3. Das BK, Shibata N, Takeuchi Y. Design and synthesis of N-nonpolar nucleobase dipeptides: application of the Ugi reaction for the preparation of dipeptides having fluoroarylalkyl groups appending to the nitrogen atom. J Chem Soc, Perkin Trans. 2002; 1:197-206.Plouvier B, Singh MP, Lown JW. Synthesis and NMR characterization of selectively ${ }^{15} \mathrm{~N}$-labelled trans- and cisbutenediamido-linked bis-netropsins. J Label Compd Radiopharm. 1995; 36:345-359.Chiriac M, Pop S, Dordea E. Synthesis of $\left[{ }^{15} \mathrm{~N}\right]$-procaine hydrochloride. J Label Compd Radiopharm. 1991; 29:1079-1084.

4. This compound is available from the Metabolomics Workbench (http:// www.metabolomicsworkbench.org/) as a reference standard. 


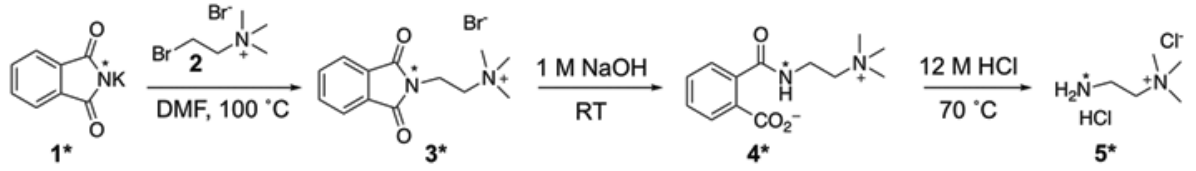

$\left[{ }^{15} \mathrm{~N}\right]$-cholamine chloride hydrochloride salt

Scheme 1.

Reported synthesis of $\left[{ }^{15} \mathrm{~N}\right]$-cholamine chloride hydrochloride $(*$ indicates the position of the ${ }^{15} \mathrm{~N}$ label). 

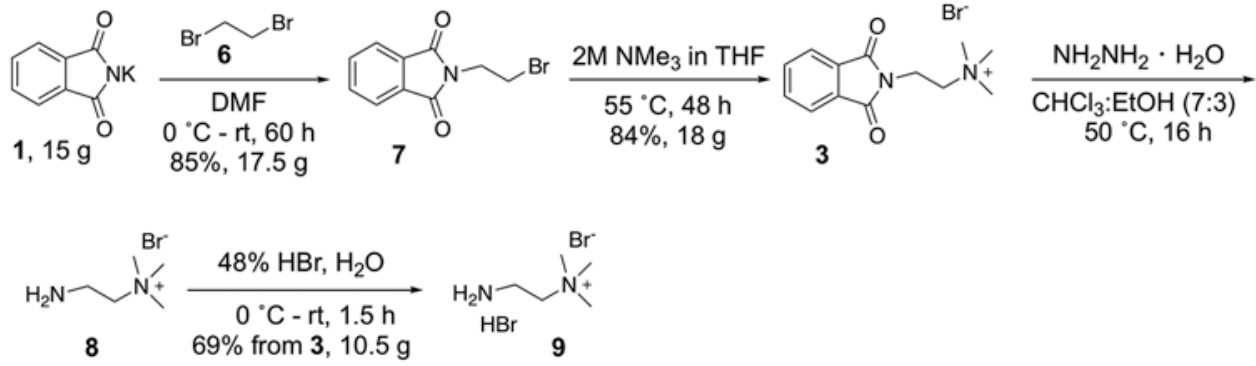

Scheme 2.

New synthesis of cholamine as its bromide hydrobromide salt. 

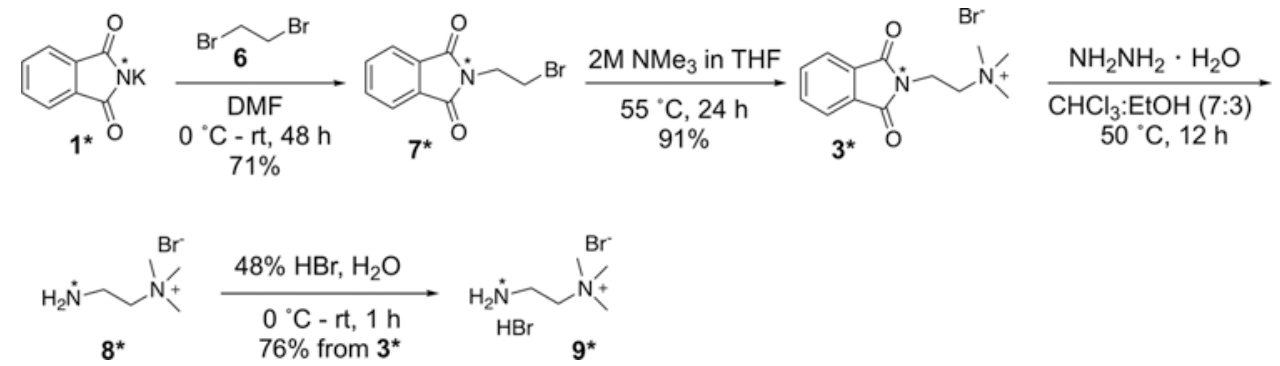

Scheme 3.

Synthesis of cholamine as its bromide hydrobromide salt $\left(*\right.$ indicates the position of the ${ }^{15} \mathrm{~N}$ label). 